\title{
Risk Factors of Obesity in Low Income Head Start Children
}

\author{
Beverly Copeland, Ph.D., RD, LD, Assistant Prof. \\ Prairie View A\&M University, USA \\ Allan A. Johnson, Ph.D., FASAHP, Prof. \\ Howard University, USA
}

doi: 10.19044/esj.2016.v12n6p1 URL:http://dx.doi.org/10.19044/esj.2016.v12n6p1

\begin{abstract}
The purpose of the study was to investigate the contributing risk factors of obesity among low income Head Start children, and to determine if there is a correlation between caregivers' perceptions of their own weight and health status, and that of their children. A cross-sectional descriptive study design was utilized. A convenience sample of 195 Head Start children and caregiver pairs were recruited from two Head Start Organizations within the District of Columbia (DC). Measured heights and weights of children and their caregivers were used to calculate Body Mass Index (BMI). A questionnaire was used to ascertain data on caregivers' perceptions of their children's weight status, doctors' diagnoses of children's weight/height status, caregivers' perceptions of their own health condition, and sociodemographic data. Results of the study showed that caregivers' perceived their overweight/obese children as being of normal weight/height status. The majority of the caregivers misperceived their own health status in a positive way. Significant relationships were found between caregiver educational level and child BMI, and between doctors' weight advice and child BMI. It was concluded that the caregivers underestimated the prevalence of overweight/obesity among their children, and overstated their own health status. Child BMI status was directly related to caregivers' educational attainment.
\end{abstract}

Keywords: Low-income children, caregiver’s perception, childhood obesity, Head Start

\section{Introduction}

The National Head Start Association (NHSA) is a nonprofit organization committed to serving children and families from low income households. Head Start is the most successful, longest-running, national 
school readiness program in the United States that serves over a million children and their families each year (NHSA, 2015). Since its inception in 1965, Head Start has provided a window of opportunity for success in life to more than 32 million low-income and other vulnerable children and their families across the United States. It was designed to help break the cycle of poverty by providing preschool children of low-income families with a comprehensive program to meet their emotional, social, health, nutritional, and psychological needs. However, it also supports the families in improving their lives. These services are still being provided today.

According to CDC, the prevalence of obesity among 2 to 4 year olds increases with the rate of poverty in their family with the rate highest among families in income- to- poverty ratio of $151-185 \%$ with $11.8 \%$ prevalence. Recent Centers for Disease Control and Prevention (CDC) reports have stated that obesity among 2 to 5 year old children decreased from $13.9 \%$ to 8.4\% in 2011-2012 (http://www.cdc.gov/obesity/data/childhood.html). However, obesity among low-income preschool children decreased from $15.2 \%$ in 2003 to $14.9 \%$ in 2010 (CDC, 2011). Therefore, obesity among low-income preschool children remains extremely high and is a cause for concern. Obesity is seen at higher rates among minority children compared to their White counterparts. The NHANES 2007-2008 data reported by Ogden et al. (2010) indicate that among 2 to 5 year old children, 9.1\% of non-Hispanic Whites, 11.4.0\% of non-Hispanic Blacks, 13.7\% of MexicanAmericans, and $14.2 \%$ of Hispanics were overweight in 2008. Thus, this trend continues as the child continues to grow. According to a CDC report (CDC, 2012), in 2011-2012, Hispanics and non-Hispanic Black youth had obesity rates of $22.4 \%$ and $20.2 \%$ respectively compared to White youth with 14.1\% (http://www.cdc.gov/obesity/data/childhood.html).

Hudson et al. (2009) reporting on the findings by Feese et al. (2003), Mason et al. (2006) and Ogden et al. (2006), stated that preschool children attending Head Start experience obesity prevalence at rates from 15.5\% to $24.0 \%$. Consequently, this is higher than the $17 \%$ reported for all U.S. children between 2 to 19 years old. Lumeng et al. (2015) reported a similar finding that one-third of the Head Start children were overweight or obese. Twenty-seven percent of those on Medicaid were overweight or obese compared to less than 20 percent of kids not on Medicaid (Lumeng et al., 2015).

Caregivers’ perceptions of children's weight have been reported to be a factor in childhood obesity. In addition, parents of children who are overweight or obese are not likely to perceive their children as such (He, 2007). Eckstein et al. (2006) reported that only $36 \%$ of the parents of children who were overweight or at risk of overweight considered them overweight or a little overweight. 
Also, misperception of children's weight were found to be more frequent among parents who were less educated and who were overweight themselves (Doolen et al., 2009; Maynard et al., 2003).

Recognizing overweight or obesity is paramount in the treatment and prevention of the disease. It has been reported that parents who do not recognize their child's overweight or obesity as a health problem are considered to be in the pre-contemplation stage of change, where the problem is not yet acknowledged, and, therefore, the importance of changes is not accepted (Duncan et al., 2011). Caregivers' misperceptions of their own weight have also been documented to be associated with lower interest in or attempts at weight loss and less physical activity.

\section{Study Objectives}

With an estimated $17 \%$ of children in the US being overweight or obese, the purpose of this study was to investigate the relationship between childhood obesity and caregivers' perceptions of their children's weight/height status in Head Start children. Much research has been conducted on parental perception of childhood overweight/obesity. However, not much research has been conducted on parental perceptions of preschoolers' obesity. In addition, less research has been reported on the Head Start population. This study adds to the scant literature on this subject.

\section{Methods}

\section{Research Design}

The research design utilized in this study was the cross-sectional descriptive survey.

\section{Subjects}

Participants in the study were 195 Head Start children between the ages of two and five years old and their caregivers. The participants were recruited from two Head Start programs in the District of Columbia. Caregivers were referred by the Head Start Nutrition Directors and teachers to the researcher. A letter explaining the project was distributed to caregivers, and signed informed consent was obtained from caregivers. All data were kept confidential. No names, addresses, or other identifying information were associated with the collected data. All signed consent forms and collected data were kept in a locked file cabinet and were accessible to the investigators only. A \$10 bank card was given to each participating family who completed all portions of the study. All procedures were approved by the University Institutional Review Board. 


\section{Procedures}

The following data were collected: weight and height, perceptions of children's overweight/obesity status by caregivers, perception of caregivers' health status, doctors' advice on children's weight status, as well as household socio-economic status and demographic data.

Subsequently, the descriptions of how these data were collected were as follows:

Weights and heights of children and caregivers were measured by the researcher using standard anthropometric procedures as described by Lohman et al. (1988). Body Mass Index (BMI) was calculated using the following formula: Weight $(\mathrm{kg}) / \mathrm{Height}^{2}(\mathrm{~m})$. Weight/height status of the children was assessed using the 2000 Centers of Disease Control and Prevention (CDC) age and gender specific BMI for age charts (http://www.cdc.gov/growthcharts/html_charts/bmiagerev.htm). BMI status of the children was classified as follows: Underweight (BMI for age and gender below the $5^{\text {th }}$ percentile); Normal (BMI for age and gender between the $5^{\text {th }}$ and the $85^{\text {th }}$ percentiles); and Overweight/Obesity (BMI for age and gender at or above the $85^{\text {th }}$ percentile). BMI status of the caregivers was classified as follows: Underweight (BMI $\left.<18.5 \mathrm{~kg} / \mathrm{m}^{2}\right)$; Normal (BMI between 18.5 and $24.9 \mathrm{~kg} / \mathrm{m}^{2}$ ); Overweight (BMI between 25.0 and $29.9 \mathrm{~kg} / \mathrm{m}^{2}$ ); and Obese $\left(\mathrm{BMI} \geq 30.0 \mathrm{~kg} / \mathrm{m}^{2}\right)$ (WHO).

Household socio-economic status, demographic data, caregiver perceptions of their children's weight/height status and of their own health status, and doctors' advice on child BMI status were collected using a questionnaire. Hence, these questions were used to find out how caregivers perceived their children's weight/height as it pertains to overweight/obesity, how caregivers perceived their own health status overall, and doctors' diagnoses of child weight/height status on annual physical examination records.

\section{Data Analysis}

The data collected were analyzed using the Statistical Package for Social Sciences (SPSS), version 19 (IBM SPSS Inc., Chicago, Illinois). Chisquare tests were used to investigate the relationships of caregivers' perceptions of their children's weight/height status to the children's BMI status; and of their own health status to their BMI status. Multiple logistic regression was used to determine variables predictive of the children's weight/height status.

\section{Results}

Results in Table 1 show the child demographics by their BMI status. Fifty-two percent of the child participants were boys and $48 \%$ were girls. This 
distribution was similar in the normal weight group but not in the underweight and overweight/obese groups. All of the underweight participants were girls, while $52 \%$ of the overweight/obese subjects were girls compared to $48 \%$ who were boys. Of those who were overweight/obese, the largest proportion (36\%) was between the ages of 36 to 47 months, followed by those who were between 48 and 59 months old (26\%), and those between 24 and 35 months of age $(25 \%)$.

Table 1. Child Demographics by BMI Status

\begin{tabular}{|c|c|c|c|c|}
\hline & Underweight $^{1}$ & Normal $^{2}$ & Overweight/Obese $^{3}$ & Total \\
\hline & Number (\%) & Number (\%) & Number (\%) & Number (\%) \\
\hline \multicolumn{5}{|l|}{ Gender } \\
\hline Male & $0 \quad(0.0)$ & 67 (54.9) & $33(47.8)$ & $100(52.4)$ \\
\hline Female & $4(100.0)$ & $55(45.1)$ & $36(52.2)$ & 95 (47.6) \\
\hline Total & $4(100.0)$ & $122(100.0)$ & $69(100.0)$ & $195(100.0)$ \\
\hline \multicolumn{5}{|l|}{ Age } \\
\hline 24-35 months & $2(50.0)$ & 32 (26.2) & 15 (21.7) & $49(24.6)$ \\
\hline 36-47 months & $1(25.0)$ & $44(36.1)$ & $25(36.2)$ & $70(36.1)$ \\
\hline 48-59 months & $0 \quad(0.0)$ & $32(26.2)$ & $18(26.1)$ & $50(26.2)$ \\
\hline $\begin{array}{l}60 \text { months or } \\
\text { more }\end{array}$ & $1(25.0)$ & $14(11.5)$ & $11(15.9)$ & $26(13.1)$ \\
\hline Total & $4(100.0)$ & $122(100.0)$ & $69(100.0)$ & $195(100.0)$ \\
\hline
\end{tabular}

Table 2 shows the socio-demographic characteristics of the caregivers by Body Mass Index (BMI) status of the children. The majority of the participants were African-Americans (86\%), followed by Hispanics (11\%). Sixty-four percent (64\%) of the caregivers reported they completed either high school or some college. Relatively few (20\%) had completed college or graduate school. There was a significant relationship between caregiver educational attainment and child BMI status $\left(\chi^{2}\right.$ statistic $\left.=8.016, \mathrm{p}=0.046\right)$. Caregivers with some college or trade school education were more likely to have children with normal BMI. Other socio-demographic characteristics (employment, annual household income, and household size) showed no significant relationship to overweight/obesity and child BMI status.

Table 2. Caregiver Socio-Demographic Characteristics by Child's BMI Status

Underweight Normal Weight Overweight/Obese Total

Race

Number (\%) Number (\%) Number (\%) N N N

$\begin{array}{crrrrr}\text { African American/Black } & 4(100.0) & 105(86.1) & 58(84.1) & 167(85.6) \\ \text { Caucasian } & 0 & (0.0) & 1(0.8) & 1(1.4) & 2(1.0) \\ \text { Hispanic } & 0 & (0.0) & 12(9.8) & 9(13.0) & 21(10.8) \\ \text { Other } & 0 & (0.0) & 4(3.2) & 0(0.0) & 4 \quad(2) \\ \text { Not Reported } & & & 1(1.4) & 1(0.5) \\ \text { Total } & 4(100.0) & 122(100.0) & 69(100.0) & 195(100.0)\end{array}$




\begin{tabular}{|c|c|c|c|c|}
\hline \multicolumn{5}{|l|}{ Gender } \\
\hline Male & $0 \quad(0.0)$ & $19(15.6)$ & $14(20.3)$ & 33 (16.9) \\
\hline Female & $4(25.0)$ & $103(84.4)$ & 55 (79.7) & $162(83.1)$ \\
\hline Total & $4(100.0)$ & $122(100.0)$ & $69(100.0)$ & $195(100.0)$ \\
\hline Education & & & & \\
\hline Never attended school & $0 \quad(0.0)$ & $1 \quad(0.8)$ & 1 (1.4) & $2(1.0)$ \\
\hline Elementary & $0 \quad(0.0)$ & $2 \quad(1.6)$ & 3 (4.3) & $5(2.6)$ \\
\hline Middle School & $0 \quad(0.0)$ & 3 (2.5) & 1 (1.4) & 4 (2.1) \\
\hline Some high school & $0 \quad(0.0)$ & $7 \quad(5.7)$ & $5(7.2)$ & $12(6.2)$ \\
\hline Diploma/GED & $1(25.0)$ & 36 (29.5) & $29(42.0)$ & 66 (33.8) \\
\hline Technical/trade school & $1(25.0)$ & $6 \quad(4.9)$ & $2(2.9)$ & $9(4.6)$ \\
\hline Some College & $1(25.0)$ & 45 (36.9) & $13(18.8)$ & 59 (30.3) \\
\hline Completed College & $1(25.0)$ & $18(14.8)$ & $7(10.1)$ & $26(13.3)$ \\
\hline Graduate School & $0(0.0)$ & $4 \quad(3.3)$ & $8(11.6)$ & $12(6.2)$ \\
\hline Total & $4(100.0)$ & $122(100.0)$ & $69(100.0)$ & $195(100.0)$ \\
\hline
\end{tabular}

The caregivers perceived their health status quite favorably (Table 3). The majority (79.5\%) perceived their health status as good or better. However, in all categories of perceived health status, the majority of the caregivers (64.9-100.0\%) were overweight or obese. The results of a chisquare test (in which the perceived health status categories of fair and poor were combined, and subjects who did not know or were unsure of their health status were omitted) indicated no significant relationship between perceived health status and their children's BMI status $\left(\chi^{2}\right.$ statistic $=9.1, \mathrm{p}=$ $0.170)$.

Table 3. Caregiver Perceived Health Status by Their Own BMI Status

\begin{tabular}{|c|c|c|c|c|}
\hline \multicolumn{2}{|c|}{ Caregivers’ Perceived Health Status } & \multicolumn{3}{|c|}{ BMI Status } \\
\hline & Number (\%) & $\begin{array}{l}\text { Underweight }^{1} \\
\text { Number (\%) }\end{array}$ & $\begin{array}{c}\text { Normal }^{2} \\
\text { Number (\%, }\end{array}$ & $\begin{array}{l}\text { Overweight, } \\
\text { Obese }^{3} \\
\text { Number (\%) }\end{array}$ \\
\hline Excellent & 58 (29.7) & $0(0.0)$ & $20(35.1)$ & 37 (64.9) \\
\hline Very Good & $46(23.6)$ & $0(0.0)$ & $11(23.9)$ & 35 (76.1) \\
\hline Good & $51(26.2)$ & $1(2.0)$ & $11(21.6)$ & 39 (76.5) \\
\hline Fair & 33 (16.9) & $0(0.0)$ & $5(15.2)$ & $28(84.8)$ \\
\hline Poor & $5(2.6)$ & $0(0.0)$ & $0(0.0)$ & $5(100.0)$ \\
\hline Don’t Know/Not Sure & $2(1.0)$ & $0(0.0)$ & $0(0.0)$ & $2(100.0)$ \\
\hline Total & $195(100.0)$ & $1(0.5)$ & $47(24.2)$ & $146(75.3)$ \\
\hline $\begin{array}{l}{ }^{1} \mathrm{Unn} \\
{ }^{2} \mathrm{~N} \\
{ }^{3} \mathrm{Ov}\end{array}$ & $\begin{array}{l}\text { erweight } \\
\text { ormal } \\
\text { rweight/Obes }\end{array}$ & $\begin{array}{r}\mathrm{BMI}< \\
18.5 \leq \mathrm{BMI} \leq 2 \\
\mathrm{BMI} \leq\end{array}$ & $\begin{array}{l}18.5 \mathrm{~kg} / \mathrm{m}^{2} \\
4.9 \mathrm{~kg} / \mathrm{m}^{2} \\
25.0 \mathrm{~kg} / \mathrm{m}^{2}\end{array}$ & \\
\hline
\end{tabular}

Table 4 shows the relationship of caregivers' perceptions of their children's weight/height status to the children's BMI. The results showed that the caregivers overestimated the prevalence of underweight and normal weight/height status, and greatly underestimated the prevalence of 
overweight/obesity. The caregivers' perception of the prevalence of underweight was 5.1\% percent compared with a prevalence of $2.1 \%$ based on BMI status. The overwhelming majority of the caregivers perceived their children to be of normal weight/height status (89.2\%), whereas only $62.6 \%$ were of normal BMI status. A minority of caregivers (5.1\%) correctly perceived their children as being overweight/obese, while $35.3 \%$ were classified as overweight or obese based on BMI. Chi-square analysis (omitting the underweight children) showed a strong significant relationship between caregivers' perceptions of their children's weight/height status and child BMI status $\left(\chi^{2}\right.$ statistic $\left.=22.4, \mathrm{p}=0.000\right)$. Caregivers were more likely to perceive their overweight or obese children as normal.

Table 4. Caregiver Perception of Child Weight/Height Status and Child BMI Status

\begin{tabular}{ccc}
\hline \multicolumn{2}{c}{ Caregivers' Perceptions of Child Weight/Height Status } & BMI Status \\
\hline & Number (\%) & Number (\%) \\
\hline Underweight & $10(5.1)$ & $4(2.1)$ \\
Normal Weight & $174(89.2)$ & $122(62.6)$ \\
Overweight/Obese & $10(5.2)$ & $69(35.3)$ \\
Not Reported & $1(0.5)$ & $0(0.0)$ \\
\hline Total & $195(100.0)$ & $195(100.0)$ \\
\hline
\end{tabular}

The majority of the caregivers (87.0\%) reported that a doctor or other health professional told them that their children were within normal BMI limits. Six percent said they were told that their children were overweight, and 6\% were told that their children were underweight. This distribution was similar across all groups. A strong significant relationship was found between doctors' and other health professionals' weight advice and child BMI status $\left(\chi^{2}\right.$ statistic $\left.=17.494, \mathrm{p}=0.001\right)$. Thus, doctors and health professionals were more likely to characterize children who were overweight or obese as normal (table 5).

Table 5. Caregiver Perception of Child Weight and Doctors Advice on Child Weight by Child BMI Status

\begin{tabular}{|c|c|c|c|c|}
\hline & $\begin{array}{l}\text { Underweight } \\
\text { Number (\%) }\end{array}$ & $\begin{array}{c}\text { Normal } \\
\text { Number } \\
(\%)\end{array}$ & $\begin{array}{c}\text { Overweight/Obese } \\
\text { Number (\%) }\end{array}$ & $\begin{array}{c}\text { Total } \\
\text { Number } \\
(\%)\end{array}$ \\
\hline \multicolumn{5}{|c|}{$\begin{array}{l}\text { Caregivers' Perceptions of } \\
\text { Child Weight }\end{array}$} \\
\hline Underweight & $2(50.0)$ & 8 (6.6) & $0 \quad(0.0)$ & $10(5.1)$ \\
\hline Normal Weight & $2(50.0)$ & $113(92.6)$ & 59 (85.5) & $174(89.2)$ \\
\hline Overweight & $\begin{array}{ll}0 & (0.0)\end{array}$ & $\begin{array}{ll}0 & (0.0)\end{array}$ & $10(14.5)$ & 10 (5.1) \\
\hline Not Reported & $0 \quad(0.0)$ & 1 (0.8) & 1 (1.4) & 1 (0.5) \\
\hline Total & $4(100.0)$ & $122(100.0)$ & $69(100.0)$ & $195(100.0)$ \\
\hline \multicolumn{5}{|c|}{$\begin{array}{c}\text { Doctors' or Health } \\
\text { Professional Advice on Child } \\
\text { Weight }\end{array}$} \\
\hline & $2(50.0)$ & $9 \quad(7.4)$ & $0 \quad(0.0)$ & 11 (5.6) \\
\hline Underweight & $2(50.0)$ & $110(90.2)$ & 58 (84.1) & $170(87.2)$ \\
\hline
\end{tabular}


Normal Weight

Overweight

No Advice

Not Reported

Total

$\begin{array}{ll}0 & (0.0)\end{array}$

2 (1.6)

10 (14.5)

$12(6.2)$

$\begin{array}{ll}0 & (0.0)\end{array}$

$1(0.8)$

$\begin{array}{ll}0 & (0.0)\end{array}$

1 (0.5)

$\begin{array}{ll}0 & (0.0)\end{array}$

$\begin{array}{ll}0 & (0.0)\end{array}$

1 (1.4)

1 (0.5)

\begin{tabular}{ccccc}
\hline Total & $4(100.0)$ & $122(100.0)$ & $69(100.0)$ & $195(100.0)$ \\
\hline
\end{tabular}

Logistic regression showed that education attainment, caregiver perception of weight/height status were significantly related to children's BMI status (Table 6).

Table 6. Logistic Regression Variables in the Equation

\begin{tabular}{cccccc}
\hline & B & S.E. & Wald & Sig & Exp(B) \\
\hline Caregivers' Educational Attainment & -0.309 & 0.141 & 4.772 & 0.029 & 0.734 \\
$\begin{array}{c}\text { Caregivers' Perception of Children’s } \\
\text { Weight }\end{array}$ & & & & &
\end{tabular}

$\begin{array}{lllll}-1.545 & 0.550 & 7.886 & 0.005 & 0.213\end{array}$

R Square $=0.310$

\section{Discussion}

Nearly ninety percent of the caregivers reported that their children were of normal weight/height, and only 5.2\% reported they believed their children were overweight or obese. However, $35 \%$ of these children were overweight or obese. This finding is in line with those from other numerous studies. For example, Jones et al. (2011), Etelson et al. (2011), Luttikhuis et al. (2010), and Pakpour et al. (2011) all reported that parents were not likely to perceive their children as overweight or obese, In addition, they mistrusted the measures used for the assessments. This, Jones et al. (2011) reasoned, was a way for parents not to face the issue and remain detached, enabling them to not face the obesity problem or make conscious efforts to amend set behaviors that contributed to the disease in the first place.

An important first step in addressing overweight/obesity is to acknowledge that there is a problem. It is equally crucial for health professionals and caregivers to identify overweight/obesity in children, especially at an early age when eating habits are not yet fully developed and are easier to correct. Parents are normally more trusting of health professionals, especially doctors. Therefore, they might be more likely to adhere to and trust their assessments than other healthcare professionals such as nurses and dietitians in schools or other settings.

In this study, thirty-five percent of the children were either overweight or obese, but only $10 \%$ of the caregivers reported being told by a doctor or other health professional that their children were either overweight/obese or underweight. This finding supports a previous study conducted by Benson et al. (2009), who reported that a large percentage of 
overweight and obese patients remain undiagnosed especially in children where the diagnosis is most crucial. In this study, a significant relationship was found between health professionals’ weight advice and child BMI status. Health professionals were more likely to misclassify children as normal weight although they were actually overweight or obese. Doctors might not readily diagnose overweight/obesity in children, as doing so requires action be taken that they are not ready or prepared to administer. Turner et al. (2009) reported in their study that practitioners do not currently view primary care as an effective treatment setting for childhood obesity. Effective treatment of obesity requires a team approach. This begins with doctors making the diagnosis and referring the child to a registered dietitian or nutritionist who will work with both parents and the child to address the problem. It is understood that health care is expensive, but Head Start programs are required to have at the least a consulting dietitian who works with nutrition personnel and staff to provide nutrition care for children and their families at no cost to caregivers. However, this setting is ideal for nutrition intervention, but each person must play his or her role in acknowledging the disease and in working together to alleviate it.

In addition, caregivers did not perceive their own overweight/obesity as a potentially detrimental health condition. This is because the vast majority of the caregivers who reported their health as 'good', 'very good', or 'excellent' were either overweight or obese at prevalence rates of $77 \%$, $76 \%$, or $65 \%$ respectively. Duncan et al. (2011) reported that weight misperception among overweight and obese adults is associated with a lower likelihood of interest in or attempts at weight loss and less physical activity. A lack of knowledge of the roles of overweight/obesity in contributing to chronic diseases might explain caregivers not recognizing obesity as a negative health condition that should be addressed. Until caregivers recognize overweight/obesity as a disease, their children stand a great chance of also developing the disease through learned behavior from their caregivers. Powell et al. (2010) reported in their study on "Body Misperception” that people who misperceived their size were happier with their health, than the ones who recognize their obesity, and were less likely to think they were at risk for developing high blood pressure, diabetes, or other life threatening diseases during their life time, even though the opposite was true. It is possible that some of the caregivers, though being overweight or obese, were not suffering from or had not been diagnosed with any chronic disease. Thus, this may explain their perceptions of their health status as good or better.

A significant relationship was found between caregivers' education and child BMI status. Caregivers who have completed some college courses or completed college were more likely to have children who were within 
normal weight status. This can possibly be explained by caregivers who have some formal education being more financially stable, and better able to read and understand food labels and the relationship food plays in the overall health of their children. Also, they might be more aware of the other risks associated with childhood obesity. Therefore, this finding is in line with a study conducted by Lazzeri et al. (2011), who reported that caregivers who had the lowest educational level were more likely to have obese children.

Based on the results of this study, it is recommended that Head Start and other preschool programs should be used as catalysts for community change. Also, it should serve as models to reinforce the healthy behaviors that children and their families need to adopt and practice throughout life. This can be accomplished by implementing and enforcing physical activity requirements (at least one hour per day) into the daily curriculum.

Caregivers and Head Start personnel should ensure that health professionals provide documentation of the children's BMI percentiles in their annual health records. This information should then be used to educate and assist caregivers in total nutritional care and the overall care of their children.

\section{Conclusion}

Caregivers who have had some college education were more likely to have children with normal BMI status than caregivers who have had no college attainment. Other socio-demographic variables among caregivers showed no significant relationships with child BMI status. Caregivers perceived their overweight or obese health condition favorably, and were more likely to perceive their overweight or obese children as normal weight. Furthermore, doctors were less likely to diagnose children as overweight/obese. Logistic regression showed that education attainment and parent/caregivers perception on weight was significantly related to children's BMI status.

\section{References:}

National Head Start Associations (2015). https://www.nhsa.org/aboutus/mission-vision-history.

Center for Disease Control and Prevention: Prevalence of Childhood Obesity in the United 2011-2012, http://www.cdc.gov/obesity/data/childhood.html

Ogden et al. (2010). Prevalence of obesity among children and adolescents: United States, trends 1963-1965 Through 2007-2008, Center for Disease Control: Division of Health and Nutrition Examination Surveys, 1-5. 
Hudson et al. (2009). Head Start children's lifestyle behaviors, parental perceptions of weight, body mass index, Journal of Pediatric Nursing, 24, 292295.

Feese et al. (2003). Prevalence of obesity in children in Alabama and Texas participating in social, programs Journal of the American Medical Association, 289 : 1780-1781.

Mason et al. (2006). Prevalence of overweight and risk of overweight among 3- to 5 year-old Chicago children, 2002-2003, Journal of School Health, 76, 104-110.

Ogden et al. (2006). Prevalence of obesity among children and adolescents: United States, trends 1963-1965 Through 2007-2008, Centers for Disease Control and Prevention: Division of Health and Nutrition Examination Surveys, 1-5.

Lumeng JC et al. (2015). Changes in Body Mass Index Associated With Head Start Participation, Journal of Pediatrics; 135:449-456

He M (2007). Are parents aware that their children are overweight or obese? Do they care? Can Fam Physician; 53: 1493-1499.

Eckstein et al. (2006). Parents' perceptions of their child's weight and health. Journal Academy of Pediatrics; 117: 681-690.

Doolen et al. (2009). Parental disconnect between perceived and actual weight status of children: A metasynthesis of the current literature. Journal of American Association of Nurse Practitioner, 21, 160-166.

Maynard et al. (2003). Maternal perceptions of weight status of children. American Academy of Pediatrics Journal, 111, 1226-1231.

Duncan et al. (2011). Does perception equal reality? Weight misperception in relation to weight-related attitudes and behaviors among overweight and obese US adults. International Journal Behavioral Nutrition and Physical Activity; 8: 20.

Lohman et al. (1988). Anthropometric standardization Reference Manual. Champaign, Illinois: Human Kinetics Publishers.

Center for Disease Control and Prevention. Clinical growth charts, http://www.cdc.gov/growthcharts/clinical_charts.htm

World Health Organization, BMI classifications. http://apps.who.int/bmi/index.jsp?introPage=intro_3.html

Jones et al. (2011). Gateshead Millennium Study core team 5. Parental perceptions of weight status in children: the Gateshead Millennium Study. Journal of Obesity; 35: 953-962.

Etelson et al. (2011). Childhood obesity: Do parents recognize this health risk? Journal of Obesity 2003; 11: 1362-1368.

Luttikhuis et al. (2010). How do parents of 4- to 5-year-old children perceive the weight of their children? Acta Paediatrica, 2010; 99: 263-267. 
Pakpour et al. (2011). Mothers' perception of obesity in School children: a survey and the impact of an educational intervention. Journal of Pediatrics; 87:169-74.

Benson L et al. (2009). Trends in the diagnosis of overweight and obesity in children and adolescents, 1999-2007. Journal of Pediatrics; 153-158.

Turner et al. (2009). Practitioners' views on managing childhood obesity in primary care: a qualitative study. British Journal of General Practice; 856862

Powell M et al. (2010). Body size misperception: A novel determinant in the obesity epidemic. Archives Internal Medicine; 170:1695-1697.

Lazzeri et al. (2011). Relationship between 8/9- Yr.-old school children BMI, parents' BMI and educational level. Nutrition Journal, 10, 76. 